\title{
Diagnostic Accuracy of Doppler Ultrasound Compared to Surgical Exploration in Torsion Testis
}

\author{
Murali Thekeveetil ${ }^{1}$, Sajitha Krishnadas ${ }^{2}$, Jaya Koothupalakal Vishwambharan ${ }^{3}$ \\ ${ }^{1}$ Department of Surgical Oncology, Government Medical College, Kottayam, Kerala, India. ${ }^{2}$ Department of \\ Radiodiagnosis, Government Medical College, Kottayam, Kerala, India. ${ }^{3}$ Department of Community Medicine, \\ Government Medical College, Thrissur, Kerala, India.
}

\section{ABSTRACT}

\section{BACKGROUND}

Twisting of the spermatic cord resulting in ischemia of the testicles known as testicular torsion is a surgical emergency. Delay in diagnosis or surgery results in loss of testicles. Doppler ultrasound of scrotum is used in evaluating acute scrotum to support or rule out a diagnosis of torsion testis. Our study compares Doppler results with findings at exploration to finding out the accuracy of Doppler diagnosis in this scenario.

\section{METHODS}

This was a record based observational cross-sectional study. Out of all cases of acute scrotum presented to a tertiary care hospital over 14 months time, those patients with Doppler evaluation done were identified $(n=52)$ and their surgical findings were compared to the Doppler findings. Diagnostic accuracy of Doppler in diagnosing torsion testis was measured using sensitivity, specificity, accuracy, and predictive values.

\section{RESULTS}

Out of these 52 cases, $44(84.6 \%)$ were testicular torsion on exploration while remaining cases were epididymo-orchitis four $(7.7 \%)$ and testicular appendage torsion four (7.7\%). Among 44 cases of torsion testis, 31 (70.5\%) patients underwent orchiectomy (70.45\%) and in remaining 13 (29.5\%) orchiopexy was done. Sensitivity of Doppler to diagnose testicular torsion was $86.4 \%$, specificity was $87.5 \%$ and accuracy was $86.54 \%$. Positive predictive value (PPV) was $97.4 \%$ and negative predictive value (NPV) was $53.8 \%$.

\section{CONCLUSIONS}

Doppler ultrasound can be used as an adjunct to clinical findings in acute scrotum. High positive predictive value suggest that all Doppler diagnosed torsion should undergo emergency exploration as it will be correct in $97.5 \%$ cases. If performing a Doppler study delays the definitive management, and if clinical findings are highly suggestive of testicular torsion, treating doctor can proceed to surgery without Doppler evaluation.

\section{KEY WORDS}

Doppler, Torsion Testis, Scrotum
Corresponding Author: Dr Murali Theke Veetil, Government Medical College, Gandhinagar, Kottayam, Kerala, India. E-mail: surgoncktym@gmail.com

DOI: $10.14260 /$ jemds/2021/619

How to Cite This Article:

Thekeveetil MT, Krishnadas S, Vishwambharan JK. Diagnostic accuracy of doppler ultrasound compared to surgical exploration in torsion testis. J Evolution Med Dent Sci 2021;10(35):3035-3039, DOI: 10.14260/jemds/2021/619

Submission 25-03-2021,

Peer Review 29-05-2021,

Acceptance 05-06-2021,

Published 30-08-2021.

Copyright (C) 2021 Murali Theke Veetil et al. This is an open access article distributed under Creative Commons Attribution License [Attribution 4.0 International (CC BY 4.0)] 


\section{BACKGROUND}

Testicular torsion is the twisting of spermatic cord which leads to ischemia of testis and it presents with acute scrotum commonly. Extravaginal torsion is seen in neonates where the processus vaginalis rotates along with the testicles. The commonest variant is intravaginal torsion where the testicles twist inside the tunica vaginalis sac. Blood supply to testicles is compromised by the torsion of spermatic cord and infarction sets in. Hence, it becomes most important to recognize torsion and operate at the earliest to save the testicle. ${ }^{1}$

Williamson historically described the chance of developing testicular or its appendage torsion up to 25 years of age as 1 in $160 .^{2}$ Lee $C$ Zhao et al. described the yearly incidence of testicular torsion below the age of 18 as 3.8 in 100,000 and the orchiectomy incidence reaches up to 41.9 percentage in those undergoing surgery for torsion. ${ }^{3} 12$ hours and 90 hours were the median duration of symptoms in patients who underwent orchiopexy and orchiectomy respectively in a study of 118 operated cases reported from China. ${ }^{4}$

In almost all cases which underwent orchiectomy, heterogenous echogenicity and decreased or absent blood flow to testicles were found in pre-operative Doppler study.

Testicular torsion being a surgical emergency should be early diagnosed and treated to prevent testicular loss. There are multiple causes of acute scrotum and recognizing torsion is mostly from history and clinical findings. Doppler ultrasound of scrotum is a simple investigation which helps the emergency clinician in decision making. It is safe, easily available and useful in selected cases of acute scrotum, though in cases of high suspicion surgeon can directly operate without it. ${ }^{5}$ In our study, we have tried to investigate the diagnostic accuracy of scrotal Doppler in testicular torsion.

Surgical exploration is considered as the gold standard investigation for diagnosis of testicular torsion and all high risk cases are expected to go for exploration without delay. ${ }^{6}$ The most common differential diagnosis of testicular torsion are testicular or epididymal appendage torsion, epididymoorchitis, hydrocele and complicated hernia. Both appendage torsion and hernia/hydrocele are surgically treated diseases, making exploration to be ideal diagnostic as well as therapeutic procedure. Both clinical findings and Doppler can misdiagnose testicular torsion and some experts are of opinion that all acute scrotum to be explored. ${ }^{7}$ In case of finding of torsed appendage testis, it can be safely excised. More than 6 hours delay in surgery might drastically reduce the chances of testicular survival. ${ }^{8}$ Manual detorsion is an option prior to surgical exploration as it may be able to reinstate the blood supply while preparing for surgery. ${ }^{1,9}$ Those testicles that are non-salvageable are excised and those that are viable are detorsed and fixed to scrotal wall to prevent further torsion.

All cases of torsion testis undergo bilateral exploration as the predisposing factors tend to be bilateral and fixing of the opposite testis is required to prevent future torsion. Torsion reduces the spermatogenic function as well as the hormonal function and can be a cause of male infertility. ${ }^{4}$ Here we compared the Doppler study result with intraoperative findings.

\section{Aims and objectives}

To study the diagnostic accuracy of Doppler in testicular torsion using intraoperative findings in surgical exploration as gold standard.

\section{METHODS}

This is a record based observational cross-sectional study. A diagnostic evaluation study was done in a tertiary care hospital in India for over a duration of 14 months from 15th October 2007 to 15 th December 2008. The study was done by obtaining data from hospital records of the patients who were admitted in the emergency department with symptoms of acute scrotum during that period. 52 patients who underwent Doppler evaluation before surgical exploration were included. There was no age limit for the patients included in the study. Age, Doppler result, surgical findings and type of surgery performed were tabulated. The diagnostic accuracy of Doppler evaluations was estimated by comparing with operative findings which is the gold standard.

As per protocol in the hospital, both general surgery department and pediatric surgery department operates on acute scrotum depending on if the patient is above or below 12 years of age. The duty surgeon from these departments in the emergency takes a call if investigations are required or can be directly shifted to operation theatre depending on the clinical scenario. As the predisposing factors of testicular torsion can be bilateral, both sides are explored and normal side orchiopexy is done whereas at the side of pain depending upon the viability of testis, either orchiectomy or orchiopexy is done.

Scrotal ultrasound evaluation with colour Doppler is done at the discretion of the clinician. As time is precious, most often than not the clinically suspicious testicular torsion cases are explored at the earliest without much time delay in diagnostic investigations.

A urine analysis is asked for in cases where epididymoorchitis is suspected. Doppler evaluation was done by trained radiologist on duty. This imaging is asked only in cases where there is non-specific clinical picture or where torsion is less likely.

But in most of the cases patient who are referred from primary care facility who would have done Doppler evaluation from the point of referral itself and they present with a Doppler result were included. In cases where scrotal Doppler was not able to give any definitive diagnosis were termed equivocal in this study.

\section{Ethical Statement}

Ethical committee clearance was obtained in Government Medical College, Kozhikode, and Kerala, India.

\section{Statistical Analysis}

Data was coded and entered in Microsoft Excel format and was analyzed using Epi Info ${ }^{\mathrm{TM}}$ software. Results obtained were expressed in terms of mean and standard deviation. 
Proportion, and diagnostic accuracy was measured using sensitivity, specificity, accuracy, and predictive values.

\section{RESULTS}

This study was done among 52 patients who underwent ultrasound Doppler scrotum before surgical exploration. Mean age of the study subjects was $16.6 \pm 7.7$ years with a median age of 17 years (range: newborn - 35 years). Out of these 52 cases, $44(84.6 \%)$ were testicular torsion on exploration while remaining cases were epididymo-orchitis four $(7.7 \%)$ and testicular appendage torsion four $(7.7 \%)$ (Table 1). Among 44 cases of torsion, 29 (65.9\%) were left sided while 15 (34.1\%) were right sided. Among 44 cases of torsion testis, $31(70.5 \%)$ patients had to undergo orchiectomy (70.45\%) and for the remaining 13 (29.5\%) cases, orchiopexy was done. (Table 2)

Among 52 study subjects, Doppler detected 39 (75 \%) cases as testicular torsion of which 38 were torsion on exploration and one false positive result was there where the actual exploratory finding was epididymo-orchitis. Eight $(15.4 \%)$ cases were diagnosed as equivocal, and five $(9.6 \%)$ cases were diagnosed as epididymo-orchitis by Doppler. Among the eight cases who were diagnosed by Doppler as equivocal, six cases turned out to be torsion, one was epididymo-orchitis and other one was testicular appendage torsion by surgical exploration. Among the five cases diagnosed by Doppler as epididymo-orchitis, none of them were having torsion. Two cases were epidedymorochitis itself and three cases were testicular appendage torsion on surgical exploration. (Table 3)

Diagnostic accuracy of Doppler in diagnosing torsion testis was measured using sensitivity, specificity, accuracy, and predictive values. Sensitivity of the Doppler was found to be $86.4 \%$ which means among 44 torsion cases diagnosed by gold standard, Doppler could detect $86.4 \%$ cases of torsion. Specificity of Doppler in this study was found to be $87.5 \%$ which means among the eight non-torsion cases diagnosed by surgical exploration, Doppler could rule out $87.5 \%$ cases of non-torsion. Accuracy was $86.54 \%$ which means in 86.54 percent of cases, the test was able to differentiate the diseased and healthy ones. Doppler had a positive predictive value of $97.4 \%$. This means out of Doppler detected all torsion cases, $97.4 \%$ cases were actual torsion cases when exploration was considered as gold standard. Negative predictive value of scrotal Doppler was $53.8 \%$, which means out of all cases which Doppler diagnosed as no torsion only $53.8 \%$ cases were actual non-torsion cases.

\begin{tabular}{|cccc|}
\hline \multirow{4}{*}{ At exploration } & Frequency & Percent \\
& Torsion testes & 44 & 84.6 \\
& Epidedymorochitis & 4 & 7.7 \\
\cline { 2 - 4 } At Doppler & Torsion appendage & 4 & 7.7 \\
& Total & $\mathbf{5 2}$ & \\
& Torsion testes & 39 & 75.0 \\
& Equivocal & 8 & 15.4 \\
& Epidedymorochitis & 5 & 9.6 \\
\hline & Total & $\mathbf{5 2}$ & \\
\hline
\end{tabular}

Table 1. Disease Distribution at Exploration and In Doppler Results

\begin{tabular}{|ccc|}
\hline & Frequency & Percent \\
\hline Orchiectomy & 31 & 70.5 \\
Orchiopexy & 13 & 29.5 \\
Total & $\mathbf{4 4}$ & $\mathbf{1 0 0 . 0}$ \\
\hline \multicolumn{3}{|c}{} \\
\hline
\end{tabular}

\begin{tabular}{|ccccc|}
\hline & \multicolumn{4}{c|}{ Exploration finding } \\
& \multirow{4}{*}{ Torsion } & Others & Total \\
\multirow{2}{*}{ Doppler result } & Torsion & $38(86.4 \%)$ & $1(12.5 \%)$ & $39(75 \%)$ \\
& & True positive & False positive & \\
& \multirow{2}{*}{ Others } & $6(13.6 \%)$ & $7(87.5 \%)$ & $13(25 \%)$ \\
& & False negative & True negative & 13 \\
& & 44 & 8 & 52 \\
\hline \multirow{2}{*}{ Table 3. Cross Tabulation of Doppler and Exploration Findings } \\
\hline
\end{tabular}

\section{DISCUSSION}

Differential diagnosis of acute scrotum includes testicular torsion, epididymitis, orchitis, incarcerated hernia and torsion of appendage testis. ${ }^{7}$ Testicular torsion being the most important diagnosis of these, as delay in management leads to organ loss. Scrotal pain at rest, nausea, vomiting, abdominal pain, history of trauma, onset during sleep are the common symptoms and absence of cremasteric reflex, skin changes of scrotum, fever and high riding testicles, are the signs which help in diagnosis of testicular torsion.2,8 Absence of unilateral cremasteric reflex is well known to be associated with spermatic cord torsion but it can also be altered in orchitis due to multiple reasons. ${ }^{9}$ Some cases of spontaneous detorsion can present as multiple episodes of scrotal pain with symptom free intervals of intermittent torsion. ${ }^{10}$ These cases also require exploration and fixation of the testicles to prevent further twist. Torsion can also occur bilaterally at the same time.11

Bell clapper deformity where the tunica vaginalis sac attaches high in the cord with completely encircling the testis and epididymis is considered as one of the commonest anomalies predisposing to torsion. In an autopsy series in incidence of this, variation in anatomy was found to be 12 percentage. ${ }^{12}$ The testicular workup for ischemia and suspected torsion (TWIST) score tries to add up the significant clinical findings and to make a score which will predict chance of torsion testis. ${ }^{13}$ Testicular swelling (2 points), hard testicle ( 2 points), absent cremasteric reflex (1 point), nausea/vomiting (1 point) and high-riding testis (1 point) are the components of this scoring system and has a high predictive value for testicular torsion. ${ }^{14}$

Ultrasound of the scrotum with colour doppler evaluation is the routinely used investigation in acute scrotum. ${ }^{15}$ In developing countries, scrotal ultrasound and colour Doppler evaluation may not be available close by or inhouse, especially at odd hours and there may be delay in obtaining this investigation. Hence, it is prudent that all cases with high suspicion of testicular torsion be explored without delay and without obtaining a Doppler evaluation if that delays definitive procedure. Findings in scrotal ultrasound in a case of testicular torsion can be heterogeneously enlarged testis and epididymis, spermatic cord whirlpool sign, redundant spermatic cord and horizontal or altered lie of the testicles. ${ }^{16}$ Diseased side is always compared to the opposite side. Doppler will show normal flow in uninvolved side and no flow in torsed testis. ${ }^{5}$ In incomplete torsion, arterial flow may still be found though veins are blocked. Ultrasound is observer dependent and result depends on available technology as well. ${ }^{17}$

By doing ultrasound scrotum, doctor cannot escape malpractice litigation. ${ }^{18}$ As testicular torsion is one of the most frequently brought up in lawsuits with missed/delayed diagnosis with loss of testicular function, treating doctor 
should be vigilant about the false negative scrotal ultrasound results. Getting ultrasound done further delays the patient care by few hours and in a disease where time matters most in organ saving, even this delay taken in investigation can be crucial. ${ }^{19}$

Baker et al. in their study found a sensitivity of 88.9 and specificity of 98.8 with colour Doppler done in cases of low suspicion or equivocal findings. ${ }^{20}$ These values are better than what our study revealed. Pinar et al. in a series of 956 Doppler done cases, got a sensitivity of $85.2 \%$ and specificity of $52.7 \%$ when compared to surgical findings. ${ }^{4}$ Burud et al. found a sensitivity and specificity of $88.24 \%$ and $68.40 \%$ while comparing ultrasound to surgery. ${ }^{6}$ Nakayama et al. had evaluated the on duty urology resident done ultrasound Doppler accuracy, they found that about 30 percent of the testicles which showed flow, actually had torsed testis in exploration. ${ }^{21}$ Kalfa et al. had conducted a multicentric trail in 11 European university hospitals with 919 patients enrolled.22 They have focused on high resolution ultrasound of the cord to find the twist and it has $96 \%$ sensitivity and 99 $\%$ specificity and these are much higher than Doppler evaluation for intratesticular blood flow in detecting torsion (76\% sensitivity). This method seems more reliable than Doppler alone.

\section{CONCLUSIONS}

In this study, a high sensitivity, specificity, and positive predictive value for Doppler was found in diagnosing testicular torsion. Torsion requires early decision making for exploration depending on history and clinical examination findings to save testicles. Scrotal Doppler can help clinician in decision making especially in cases where clinical findings are inconclusive. We are of the opinion that in cases of high clinical suspicion, surgeon can go ahead with exploration without a Doppler evaluation.

\section{Limitations of This Study}

There are few limitations for this study. Firstly, there is no standardization of personals or ultrasound Doppler machines, or procedure involved in scrotal Doppler ultrasound. This is because they are from different radiologists at different places at the primary care centers and our institution radiology. Second is that, other than those cases who had a Doppler done from primary care center, our protocol is not to wait for Doppler from inside the hospital if clinical suspicion is high for torsion. Hence, it is possible that more of non-torsion cases came for Doppler from inside the hospital. Thirdly, as most are referred cases, it is possible that a qualified hand has evaluated the patient at primary care facility itself and only patients requiring exploration are referred to our hospital. These biases might have influenced the results.

Data sharing statement provided by the authors is available with the full text of this article at jemds.com.

Financial or other competing interests: None.

Disclosure forms provided by the authors are available with the full text of this article at jemds.com.

\section{REFERENCES}

[1] Sharp VJ, Kieran K, Arlen AM. Testicular torsion: diagnosis, evaluation and management. Am Fam Physician 2013;88(12):835-40.

[2] Williamson RC. Torsion of the testis and allied conditions. Br J Surg 1976;63(6):465-76.

[3] Zhao LC, Lautz TB, Meeks JJ, et al. Pediatric testicular torsion epidemiology using a national database: incidence, risk of orchiectomy and possible measures toward improving the quality of care. J Urol 2011;186(5):2009-13.

[4] Pinar U, Duquesne I, Lannes F, et al. The use of Doppler ultrasound for suspected testicular torsion: lessons learned from a 15-year multicentre retrospective study of 2922 patients. Eur Urol Focus 2021;:S24054569(21)00054-7.

[5] Mernagh JR, Caco C, De Maria J. Testicular torsion revisited. Curr Probl Diagn Radiol 2004;33(2):60-73.

[6] Burud IAS, Alsagoff SMI, Ganesin R, et al. Correlation of ultrasonography and surgical outcome in patients with testicular torsion. Pan Afr Med J 2020;36:45.

[7] Srinivasan A, Cinman N, Feber KM, et al. History and physical examination findings predictive of testicular torsion: an attempt to promote clinical diagnosis by house staff. J Pediatr Urol 2011;7(4):470-4.

[8] Fujita N, Tambo M, Okegawa T, et al. Distinguishing testicular torsion from torsion of the appendix testis by clinical features and signs in patients with acute scrotum. Res Rep Urol 2017;9:169-74.

[9] Soyer T, İnal E, Boybeyi Ö, et al. Electrophysiologic evaluation of cremasteric reflex in experimental orchitis. J Pediatr Urol 2013;9(6 Pt B):1098-102.

[10] Obi AO. Intermittent testicular torsion. Niger J Clin Pract 2017;20(10):1273-6.

[11] Pogorelić Z, Jukić M, Škrabić V, et al. Bilateral simultaneous testicular torsion in a newborn: report of a case. Acta Medica (Hradec Kralove) 2017;60(3):120-3.

[12] Caesar RE, Kaplan GW. Incidence of the bell-clapper deformity in an autopsy series. Urology 1994;44(1):1146.

[13] Roberts CE, Ricks WA, Roy JD, et al. Testicular workup for ischemia and suspected torsion in pediatric patients and resource utilization. J Surg Res 2021;257:406-11.

[14] Pradyumna P. Validation of the Testicular Workup for Ischemia and Suspected Torsion (TWIST) score in the diagnosis of testicular torsion in children with acute scrotum. Indian Pediatr 2020;57(10):926-8.

[15] Patriquin HB, Yazbeck S, Trinh B, et al. Testicular torsion in infants and children: diagnosis with Doppler sonography. Radiology 1993;188(3):781-5.

[16] Bandarkar AN, Blask AR. Testicular torsion with preserved flow: key sonographic features and valueadded approach to diagnosis. Pediatr Radiol 2018;48(5):735-44.

[17] Barbosa JABA, Denes FT, Nguyen HT. Testicular torsioncan we improve the management of acute scrotum? J Urol 2016;195(6):1650-1.

[18] Gaither TW, Copp HL. State appellant cases for testicular torsion: case review from 1985 to 2015. J Pediatr Urol 2016;12(5):291.e1-e5. 
[19] Chan EP, Wang PZT, Myslik F, et al. Identifying systems delays in assessment, diagnosis and operative management for testicular torsion in a single-payer health-care system. J Pediatr Urol 2019;15(3):251.e1-e7.

[20] Baker LA, Sigman D, Mathews RI, et al. An analysis of clinical outcomes using color doppler testicular ultrasound for testicular torsion. Pediatrics 2000;105(3 Pt 1):604-7.
[21] Nakayama A, Ide $H$, Osaka $A$, et al. The diagnostic accuracy of testicular torsion by doctors on duty using sonographic evaluation with color Doppler. Am J Mens Health 2020;14(5):1557988320953003.

[22] Kalfa N, Veyrac C, Lopez M, et al. Multicenter assessment of ultrasound of the spermatic cord in children with acute scrotum. J Urol 2007;177(1):297-301. 